Brief Communication

\section{SARS-CoV-2 infection-associated detrimental effects on the various human organs}

\author{
Haleema Nadeem ${ }^{1}$, Mahnoor Ayesha ${ }^{1}$, Umar Saeed ${ }^{2,3 *}$, Zahra \\ Zahid Piracha ${ }^{2,3}$, Rafia Tahir ${ }^{1}$, Noor-Ul-Ain', Farrah Mehtab1, \\ Rida Fatima ${ }^{1}$ and Rizwan Uppal ${ }^{2}$
}

${ }^{1}$ Department of Biological Sciences, International Islamic University, Islamabad, Pakistan ${ }^{2}$ Department of Research and Development, Islamabad Diagnostic Center, Islamabad, Pakistan ${ }^{3}$ Department of Medical Research, International Medical Research Center, Islamabad, Pakistan

\section{Abstract}

The SARS-Cov-2 virus was firstly identified in Wuhan, China and caused catastrophic destruction all over the world. COVID-19 virus primarily effects lungs of its hosts and impairs it in number of ways. It can also damage multiple organs like Heart, kidney, endocrine glands, skin, brain and several others. Kidneys are also damaged to a great extent. In Heart it can cause acute coronary syndrome, Heart failure, Myocardial infarction. SARS-CoV-2 effect brain especially psychologically. It also causes serious lymphocyte apoptosis. It also neutralizes human spleen and lymph nodes. SARS-CoC-2 can be harmful for those having already liver diseases. Similarly, SARS-CoV-2 has a direct impact on endocrine glands. It is responsible for the various injurious changes in hormones, causes various diseases like acute pancreatitis, decrease in $\mathrm{GH}$, hypoparathyroidism etc. and lead to cause tissues damage in glands. It also some minor effects on nose, and respiratory pathways. It also has some minor effects on eyes and ears whereas it causes several devastations in GIT.

\section{More Information}

*Address for Correspondence: Dr. Umar Saeed, Department of Research and Development, Islamabad Diagnostic Center, Islamabad, Pakistan, Email: umarsaeed15@yahoo.com

Submitted: September 20, 2021

Approved: October 25, 2021

Published: October 26, 2021

How to cite this article: Nadeem $\mathrm{H}$, Ayesha M, Saeed U, Piracha ZZ, Tahir R, et al. SARSCoV-2 infection-associated detrimental effects on the various human organs. Int J Clin Virol. 2021; 5: 072-081.

DOI: 10.29328/journal.ijcv.1001038

ORCiD: orcid.org/0000-0002-9740-0371

Copyright: @ 2021 Nadeem H, et al. This is an open access article distributed under the Creative Commons Attribution License, which permits unrestricted use, distribution, and reproduction in any medium, provided the original work is properly cited.

Keywords: SARS-CoV-2; COVID-19; Heart; Brian; Lungs; Kidneys; Myocarditis; Conjunctivitis; Acute pancreatitis; COVID-19 acute respiratory syndrome; Lymph follicle exhaustion; Splenic knob; Histocyte hyperplasia; ACE

\section{Check for updates}

OPEN ACCESS

\section{Introduction}

In December 2019, there was an outburst of a virus in Wuhan city, the capital of Hubei territory in China [1]. Coronavirus illness (COVID-19) is caused by SARS-COV2, and is considered a causative operator of a dangerous malady brought about broad concern in worldwide open wellbeing. Coronavirus is one of the biggest pathogens that target the human respiratory tract. Past coronavirus episodes have included extreme intense respiratory disorder (SARS) -CoV and Center East Respiratory Disorder (MERS) -CoV, which have long been known to be exceptionally debilitating to open wellbeing. In late December 2019, a few patients were conceded to the healing Centre whose beginning determination was pneumonia with obscure cause. These patients were related to a wild animal market in Wuhan, Hubei Territory, China $[2,3]$. In fundamentally sick patients, different organs are regularly influenced. The virus ties to angiotensin- converting enzyme 2 (ACE2) receptors present in vascular endothelial cells, lungs, heart, brain, kidneys, intestine, liver, pharynx, and other tissue [4].
Viral pathogens are increasing worldwide and it is anticipated that soon viruses would emerge as highly dangerous entities. Prevention is better than cure. Identification of epidemiological patterns of SARS-CoV-2 spread and dissemination of knowledge and awareness related to risk factors associated with viral transmission in different populations at risk; could prevent emergence of epidemics. The prevalence of SARS-CoV-2 infections are unfortunately increasing day by day due to limited awareness among general population. The aim of current study was to determine the impact of SARS-CoV-2 infection on several human body organs (Figure 1).

\section{Impact of SARS-CoV-2 on human hearts}

COVID 19 affect the heart by causing the acute coronary syndrome, congestive heart failure, myocarditis, and arrhythmias [5]. There is confirmation that patients with COVID-19 have heightened thromboembolic threat with a diversification of indication in connection with ischemic stroke, deep vein thrombosis, acute pulmonary embolism, acute myocardial infarction, systemic arterial embolism [6]. 


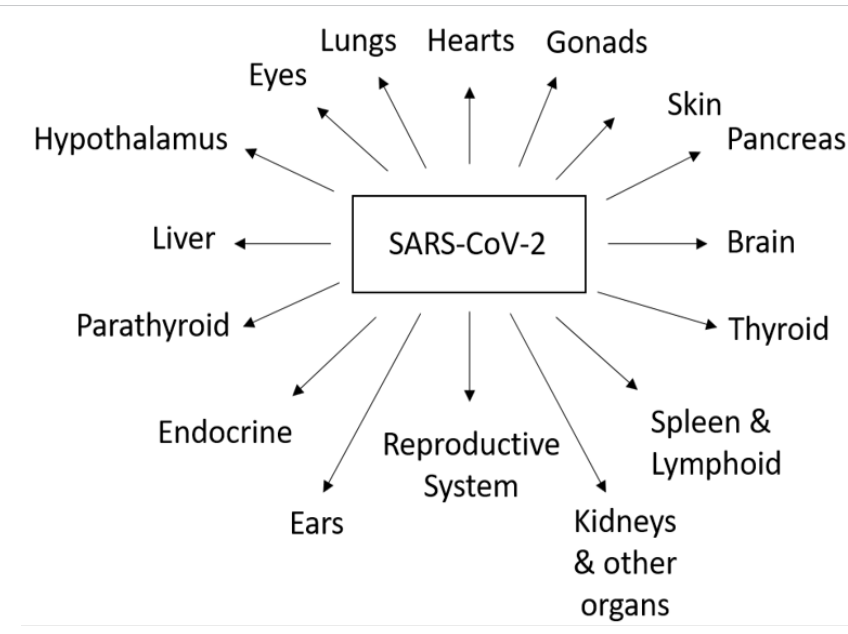

Figure 1: Effects of SARS-CoV-2 on different human body organs.

In COVID-19 patients the virus itself cause Cardiac injury. The virus attacks via angiotensin-converting enzyme 2 (ACE2) receptors which can cause pneumonia, acute myocardial injury, and chronic cardiovascular damage [7]. There was a case reported in which a patient has acute pericarditis and left ventricular dysfunction but that patient has no respiratory tract symptoms [8]. ACE2 is also related to the reninangiotensin-aldosterone system (RAAS) which result in the production of Angiotensin-II (Ang-II), a molecule associated with many cardiovascular diseases. When Ang-II binds to angiotensin type-1 receptor, which results in vasoconstriction, inflammatory responses, increased blood coagulation [9].

\section{SARS-CoV-2 effects on reproductive organs}

Recent studies showed that COVID-19 also affect male reproductive organ causing male infertility. Early studies shows that male is more likely to get infected than female [10]. The possible threat of COVID-19 affecting fertility is due to virus angiotensin-converting enzyme 2 (ACE2) enzyme receptor entry on testes, a reduction in important sex hormone ratios and COVID-19-associated fever [11]. Surprisingly ACE2 expresses higher in testes [12]. Further studies show that ACE2 has the highest expression in spermatogonia, leyding and Sertoli cells as compared to spermatocytes and spermatids [13].

\section{COVID-19 associated indirect harmful effects on skin}

Skin- related problems during the COVID-19 pandemic were also observed giving rise to new challenges for Dermatologists. Studies have shown that these problems are caused due to prolonged contact with personal equipment like N95 masks, latex gloves and protective clothing and excessive personal hygiene. which results in many skins manifestation like Pressure injury, contact dermatitis, itch, pressure urticaria, and exacerbation of preexisting skin diseases, including seborrheic dermatitis and acne, have been described [14]. Wearing N95 mask (National Institute of Occupational Safety and Health) which can filter $95 \%$ of infectious particle of COVID-19 effectively, this mask that fits closely to the facial skin. Most adverse reaction of using N95 mask is acne, itching and rash COVID-19 also spread through physical contact so by using latex gloves dry skin, itching and rash were observed [15].

\section{Impact of SARS-CoV-2 on human eyes}

Recent studies showed that the Respiratory tract and faecal-oral route should not be considered as the only routes of transmission of COVID-19 in fact eyes are also considered as transmission routes [16]. In the ocular surface which includes the outer layer of the cornea, inside the eyelids and white of the eye Angiotensin-converting enzyme 2 (ACE2) and TMPRSS2, receptors through which SARS COV-2 attack are found in patients which proves its transmission through eyes [17]. Further research has shown that around one-third of the patients with severe SARS Cov-2 infection develop ocular abnormalities like conjunctivitis [18]. Along with conjunctivitis other abnormalities like anterior uveitis, retinitis, and optic neuritis are also reported in COVID-19 patients [19].

\section{COVID-19 associated central nervous system and brain disorders}

SARS-CoV-2 is a respiratory pathogen, there are reports of neurological appearances, such as epileptic seizures and encephalitis that will recommend a CNS inclusion of the disease $[20,21]$. Encephalitis may be a result of infection or viral proteins having entered the brain. SARS-CoV-2 mRNA has been recuperated from the cerebrospinal fluid, recommending it can cross the blood brain barrier (BBB) [22,23]. SARS-CoV-2 can contaminate neurons in a brain Sphere model [24]. SARSCoV-2 might actuate changes within CNS without specifically crossing the BBB, as COVID-19 is related with cytokine storm, and numerous cytokines cross the BBB to influence CNS work [25]. SARS-CoV-2 spike protein can straightforwardly influence the obstruction work of the BBB which gives more profound knowledge into the neuropathology related with COVID-19. Most likely, the interaction between SARS-CoV-2 and the BBB is multifocal and includes reversible activation at more than one receptor or signaling cascade [26]. Compelling proves illustrate that SARS-CoV connects to the cell layer by binding to human angiotensin-converting chemical 2 (hACE2), presently too known to be the SARS-CoV-2 utilitarian receptor [27]. The study of human tissue has shown a copious nearness of these receptors not as it were within the epithelia of the lungs and the small intestine bit also in arterial and venous endothelial cells and arterial smooth muscle in all organs considered, counting the brain [28]. Comparative to HCoVOC-43, a demonstrate in vivo of SARS-CoV disease proposed that the infection enters the brain through the olfactory bulb, and after that a trans neuronal spread seem occurs [29]. Brain tissue specimens of patients with SARS-CoV were examined under the microscope which showed the degeneration of neurons, necrosis, edema, extensive glial cells hyperplasia, and cellular infiltration of the vascular dividers by monocyte and lymphocytes [30]. It is also suggested that tall expression 
of ACE2 with in central glial substance and ventricles may give another potential path way for SARS-CoV-2 or SARS-CoV entering the CSF and/or spreading around the brain [31]. SARS-CoV particles are primarily found within the neurons with in the brain tests from SARS patients [32].

Because of money related troubles and social segregation due to COVID-19, numerous mental issues can emerge. They can be postponed by months. There is an increment in "passing of lose hope" from substance mishandle or suicide. The hazard is more prominent among people with dementia, mental sickness, and extreme invertedness. In individual and online communication with companions and back experts is beneficial [33]. On release from ICU, a third of the patients have dysexutive disorder comprising of carelessness confusion or ineffectively organized development in reaction to command [34]. A few patients who recover from COVID-19 create mental wellbeing issues. These incorporate uneasiness, sadness and post-traumatic stretch disorder (PTSD). Long impacts can incorporate advancement of Alzheimer's or Parkinson's disease [35].

\section{COVID-19 effects on spleen and lymphoid organs}

SARS-Cov-2 might specifically taint auxiliary lymphoid organs to cause cell death. Immunohistochemistry illustrated ACE2, the potential receptor SARS-CoV-2, communicates on tissue-resident CD169+ macrophages in spleens and LNs. SARS-CoV-2 disease actuates extreme tissue harm counting lymph follicle exhaustion, splenic knob decay, histocyte hyperplasia and lymphocyte diminishments. Besides, in situ TUNEL recoloring outlined that viral disease leads to serious lymphocyte apoptosis, which could be intervened by viral antigens actuating Fas upregulation. Moreover, SARS-CoV-2 too triggers macrophages to deliver IL-6, a proinflammatory cytokine that specifically advances lymphocyte necrosis. Collectively these comes about illustrates that SARS-CoV-2 straightforwardly neutralizes human spleens and LNs through tainting tissue-resident CD169+ macrophages [36].

\section{SARS-CoV-2 associated liver damage}

In SARS, the most elevated mortality rates were watched within the elderly and grown-ups with fundamental liver disease [37]. In this manner, it should be anticipated that the patients with COVID-19 are too more defenseless to hepatic harm [38]. It is an additionally conceivable that the liver impedance is due to medicate hepatotoxicity, which might clarify the expensive variety watched over the diverse cohorts. In expansion, immune mediated irritation, such as cytokine storm and pneumonia associated hypoxia, might to contribute to liver damage or indeed create into liver disappointment in patients with COVID-19 who are basically ill. Liver harm in gentle cases of COVID-19 is regularly transitory and can return to typical without any uncommon treatment [39].

\section{COVID-19 effects on endocrine glands}

In a general point of view, this definite pathogenetic effect of COVID-19 may affect vascularized organs, such as the endocrine glands and in certain those with a very compact vascular network including pituitary [40].

\section{COVID-19 associated pancreas diseases:}

In a study it is suggested that there is a direct impact of COVID-19 infection on the pancreas [41]. It is reported that acute pancreatitis in patients with COVID-19 were first published in China, and then all over the world [42]. Even though acute pancreatitis is not an unusual condition, this case report suggests chance of an uncommon and direct causal relation between COVID-19 infection and acute pancreatitis. This can aid physicians in decision making, expecting COVID-19 as a possible cause [43]. Two of the three family members were identified with acute pancreatitis related with SARS-CoV-2 [44]. The COVID PAN study proposes that acute pancreatitis in patients with COVID-19 is more regularly severe than in patients without COVID-19, some patients develop COVID-19 symptoms and abdominal pain at the starting of the infection, and others have acute pancreatitis days after COVID-19 is diagnosed [45]. Pancreatic injury in COVID-19 might be caused directly by viral involvement or secondary from enzyme abnormalities in the context of severe illness without substantial pancreatic injury [46]. NHE is present in all tissues and there is rich NHE2 isoform in the pancreas. Therefore, extreme, and constant NHE activation with COVID-19 infection can eternally damage the endocrine pancreatic tissue [47].

\section{COVID-19 effects on Hypothalamus/pituitary gland}

The first observation regarding SARS-CoV-2 was reported and found that the presence of SARS-CoV-2 in the cerebrospinal fluid of COVID-19 patients, suggesting a SARS-CoV-2 Is spreading in the CNS [48]. A practical study performed in 40 COVID-19 patients with non-severe symptoms matched to 54 healthy controls revealed a major decrease in GH and IGFBP-3 during hospitalization [49]. Patients with diabetes insipidus who grow respiratory complications of COVID-19 are at expressively increased risk of dysnatremia and should have a close monitorization [50].

\section{SARS-CoV-2 effects on thyroid}

For thyroid gland it is found that the degree of the decline in TSH and TT3 levels was positively associated to the severity of COVID-19 infection. All enrolled patients had no earlier known thyroid disease and no medical record inducing thyroid function [51]. A different group did a study in 274 patients with SARS-CoV-2 and found that TSH and FT3 concentrations were considerably lower in patients who died (n.113) than those who recovered (n.161), while FT4 levels were not statistically different [52], in other studies, it is exposed a direct damage of thyroid tissue in response to COVID-19 infection telling some patients with neck pain radiated to the jaw and concomitant asthenia [53]. FT3 levels were significantly lesser in patients with severe COVID-19 disease and FT3 levels lower than 
$3.10 \mathrm{pmol} / \mathrm{L}$ expected morality freely from all other causes [54]. The Sex of patients with thyrotoxicosis and COVID-19 infection was mainly male and low TSH and FT3 level were related with normal/elevated FT4 level [55].

\section{COVID-19 associated parathyroid gland defects}

It is found that two third of patients with novel coronavirus disease (COVID-19) had hypocalcemia [56]. SARS-CoV-2 might have the prospective to directly attack the parathyroid glands by binding with acidophilic cells ACE2 receptors. This could explain the conclusion of hypoparathyroidism in the COVID-19 patient [57]. COVID-19 might affect the function of parathyroid glands by two possible ways; directly through the occupation of parathyroid gland tissues by SARS-CoV-2 virus, and indirectly secondary to respiratory failure and chronic respiratory alkalosis [58].

\section{COVID-19 associated adrenal gland defects}

Patients with COVID-19 infection may be inclined to corticosteroid insufficiency (CIRCI) due to both direct viral adrenal cell damage and adrenal inflammatory/autoimmune processes [59]. It is postulated that the arrangement of both COVID-19 infection and APLS was responsible for adrenal failure [60]. During hospitalization, in COVID-19 patients, Abdomen CT scan revealed increased size and blurring of both adrenals expressive for acute bilateral adrenal hemorrhage (BAH) [61].

\section{SARS-CoV-2 effects on gonads}

A recent study for testis in 81 men with COVID-19 showed that serum total testosterone (T) was lesser (although not statistically significant), while serum LH was significantly higher as compared to 100 age-matched healthy men [62]. In addition, SARS-CoV infection was presented to suggestively reduce serum testosterone in male mice [63]. Indications about the involvement of ovary in SARS-CoV-2 infection are absent. Hence, post-mortem pathological studies on consistent series are essential to explain any option of COVID-19 infection in the ovary and its potential effect on female fertility [64].

\section{COVID-19 effects on lungs}

According to research, the most effected organ due to SARS Cov-2 is Lungs [65]. It damages lungs in number of ways including impairment of capillaries, alveolar epithelium, and hyaline membrane [66]. Studies predict that even after recovery, the Lungs are so severely damaged that it could take months or years to recover completely to normal lung function [67]. ARDS or acute respiratory distress syndrome in a group of complications that causes fluid to leak into lung space ultimately causing lower oxygen levels in body and breathing difficulties. ARDS is usually secondary to some an already prevailing disease [68]. The most common impact of COVID-19 on lungs is development of ARDS during or after infection. This condition has been referred to as COVID-ARDS or CARDS (COVID Acute Respiratory Distress Syndrome). Studies suggest that among people diagnosed with covid19 $40 \%$ of them will develop ARDS with $20 \%$ of them being in critical condition [69].

Another serious impact of COVID-19 is growth of Pulmonary Fibrosis in lungs. Pulmonary Fibrosis is a group of diseases which effect lung tissue resulting in its thickness and scarring of connecting tissues which ultimately leads to hardening and thickening of these tissues and damaging the Alveoli. This causes breathing problems including shortness of breath and difficulty in breathing [70]. Although long term complications related to fibrosis after COVID are still being studied but already existing data and research done on patients recovered from COVID-19 suggests that there is a chance to develop fibrosis related complications in more than one third of these people. Moreover, among those recovered patients, decreased Capacity of the lungs for carbon monoxide (DLCO) was observed in $47 \%$ of total people, while $25 \%$ of those people were identified with lower total lung capacity (TLC). These after effects were more complicated in people who had a history of any severe illness $[71,72]$.

\section{SARS-CoV-2 effects on kidneys}

Kidney is considered one of the main targets covid virus infection. The exact mechanism between COVID-19 and Acute Kidney Injury (AKI) is still not clear and changeable depending on demographics with percentage between 0.9\% - 29\% [73]. Acute Kidney Injury (AKI) which is also called Acute Renal Failure (ARF) is a type of sudden kidney failure or damage which occurs in a small span of time somewhere between few hours up to few days. AKI disturbs the right balance of fluids in body due to buildup of waste products in blood which exerts additional pressure on kidney function. It is usually secondary to some already prevailing illness and most commonly occurs in patients who are already in Hospital especially ICU due to that primary illness. It also effects other organs like heart, lungs and brain [74].

Initial studies suggested that AKI occurs in 3\% - 9\% of COVID-19 patients but recent studies show that it is present in more than $15 \%$ of people recovered or recovering from COVID infection $[75,76]$. People diagnosed with Acute Kidney Injury during COVID infection have lower rate of survival. It also one the major complication in COVID related deaths. In people diagnosed with COVID, an immediate Proteinuria (increased levels of protein in urine) have also been observed [77]. Among people who are the maximum risk of COVID and COVID related complications, Kidney Transplant Recipients (KTR) were included [78]. Study was done to observe kidney function of 193 people diagnosed with COVID-19. Increased levels of Blood Urea Nitrogen (BUN) were seen in 31\% of those people while increased serum creatinine was noticed in $22 \%$ of total people. In a similar study done on 147 COVID patients, $60 \%$ people showed proteinuria and $48 \%$ showed hematuria. 


\section{SARS-CoV-2 effects on ears}

The impact of anti-infection treatment and rehabilitation on the outside ear flora as examined in 131 youngsters $[79,80]$. They surveyed the pervasiveness of centre ear emanation (MEE) at the hour of BMT during comparative time-frames in the prior year during and after MSHO in this pandemic year [81]. People with disability particularly with hearing weakness face considerably more trouble. They can't get their standard assessment and treatment, the upkeep of their hearing reclamation gadgets has additionally observed to be bulky [82].

\section{SARS-CoV-2 effects on throat}

COVID-19 analysis fundamentally relies upon constant RT-PCR test of throat swabs [83]. They directed an imminent multi-focus cross-sectional investigation to contrast prompted sputum with throat swabs for SARS-CoV-2 recognition [84]. Throat become itchy, scratchy, and sore in COVID-19. Half of the people experience a sore throat who are ill with COVID-19.

\section{SARS-CoV-2 related upper and lower airways disorders}

On upper and lower airways estrogen has a set up benefice effect [85]. Chronic obstructive respiratory disease, airway epithelial damages, tobacco-smoke exposure, cardiovascular and cerebrovascular diseases are the dangerous factors for patients with cancer of upper and lower airways [86].

\section{COVID-19 related effects on human nasopharyngeal region}

The presence of antigen introducing cells in the nasal and oral mucosa, SARS-CoV-1 had the option to avoid this intrinsic insusceptible reaction in Rhesus macaques (RM) [87]. COVID-19 is passed on through respiratory droplets. These are tiny droplets that come from your nose and mouth when you sneeze, cough, and breathe.

\section{SARS-CoV-2 effects on gastrointestinal tract GIT}

SARS-CoV-19 infected many organ systems other than respiratory system, including hepatic system or digestive system, in digestive system, GIT is affected a lot because of the presence of ACE 2 receptor on the surface of GIT. Some of the gastrointestinal symptoms are following, diarrhoea, vomiting, nausea, loss of appetite and pain in abdomen $[88,89]$. Symptoms such as fever, myalgia, and cough might be start along with the above-mentioned symptoms or before the showing of gastrointestinal symptoms. There are a lot of ACE2 receptors in lower GI tract. Intact infectious virus or only RNA and protein fragments of the virus are also found in patient's stool. It took longer time to clean-up if the patient has virus in his/her stool. GI Symptoms are existed in exceedingly small percentage in patient, many patients get rid of virus via stools [89]. Following is the pervasiveness of gastrointestinal symptoms which is ranged from $6.8 \%$ to $61.3 \%$, which includes anorexia (12.1\% to $40.0 \%$ ), diarrhoea
( $8.14 \%$ to $33.7 \%$ ), abdominal pain ( $0 \%$ to $14.5 \%$ ), nausea/ vomiting (1.53\% to $26.4 \%$ ) [90].

SARS-CoV-2 is the member of family beta coronavirus, which goes in to the cells via the ACE2 receptor [91]. ACE2 found in abundance in the epithelia of the intestine as well as liver in humans, which may be provide the confirmation for the possibility of this route for COVID-19. Expression of ACE2 is primarily found on the luminal surface of differentiated epithelial cells of small intestine. In addition, in the crypt cells and the colon, lower expressions are observed [92].

Here is a study for analyzing gastrointestinal symptoms in COVID-19 patients in China. These are analyzed findings by 35 studies, which includes 6686 patients with COVID-19, who have all the symptoms of COVID-19. In 29 studies, it is reported that gastrointestinal symptoms in patients with COVID-19 were on processing and the pooled universality of simultaneous diseases of digestive system was $4 \%$. The pooled commonness of digestive symptoms was $15 \%$ with vomiting (nausea), loss of appetite and diarrhoea, were the three most familiar symptoms. After Subgroup analysis, it was noted that there were higher rates of abdominal pain in patients with severe COVID-19 as compared to those who have non-severe disease. COVID-19 patients who were children had a familiar universality of gastrointestinal symptoms as of adult patients. $10 \%$ of patients grant with gastrointestinal symptoms solitary having no respiratory features. Delayed diagnosis was the reason for the patients who have gastrointestinal system involvement along with COVID-19. Above study manifested those digestive symptoms are unfamiliar in patients with COVID-19. There is need of more attention for these types of patients [93]. Affirmation recommends that for SARS-CoV-2 infection, gastrointestinal tract could be act as viral target. SARS-CoV-2 receptor ACE2 have high expressions in the GI tract and have an association with digestive symptoms, along with this bleeding and inflammation are noted in the intestine of patient of COVID-19 [94], which causes impact on the intestinal immune system and exert influence on whole body's immune system, thus deteriorating the disease procedure of COVID-19 in the lungs and other organs $[95,96]$.

Moreover, during SARS-CoV-2 infection, viral balance in the GI tract could be tangled which could further affects the homeostasis of the beneficial bacteria found in gut [94]. ACE2 has high expression in gastrointestinal (GI) cells, like in esophageal epithelial cells and the absorptive enterocytes from colon and ileum [97-100]. In a study of 1141 confirmed COVID-19 cases 183 (16\%) patients with gastrointestinal symptoms was observed. The following are the symptoms which are included in gastrointestinal symptoms, like diarrhea 68 (37\%), vomiting 119 (65\%), nausea 134 (73\%), loss of appetite 180 (98\%) and abdominal pain 45 (25\%) [101]. In another study, in which pediatric COVID-19 patients were observed diarrhea was noted in 3 out of 10 pediatric COVID-19 patient [102]. Likewise, of a relative study of 244 COVID-19 
infected children, 34 of them designates GI symptoms, including vomiting 23 (67.7\%), diarrhoea 15 (44.1\%), abdominal pain 4 (11.8\%), and decreased feeding 8 (23.5\%) [103]. Expression of ACE2 has abundancy in the epithelial cells of the GI tract is also investigated and the expression levels are higher as compared to lung [101-106]. The function of ACE2 in amino acid transport emphasizes the importance of ACE2 in the GI tract [107]. The C-terminal domain of ACE2 is a duplicate of renal transmembrane glycoprotein which plays a part in managing of neutral amino acids. It is investigated that ACE2 shares $50 \%$ of its realm with collection [108]. Since both ACE2 and collection are 50\% alike, it is advised that they might have same function as well. After that it is noted that ACE2 does play viral role in the transport of amino acids and this had an intense impact on the good microbes in GI tract, which further effects the immune system of digestive system [92].

Expression of ACE2 on the luminal epithelial cells of the GI tract advices the probability of another site or secondary site for entry SARS-CoV-2 [106]. Likewise, yet, SARS-CoV-2 infection is indicated by respiratory symptoms urging droplet transmission, gastrointestinal indications for example diarrhea, vomiting, and abdominal pain, are also observed [109]. The GI symptoms appear to lead to the typical respiratory symptoms of COVID-19. SARS-CoV-2 RNA is recognized in anal and rectal swabs and specimens of stool of COVID-19 patients, advocating the fecal-oral route of transmission [110]. Immunohistochemical studies presented the presence of viral nucleocapsid protein in the cytoplasm of gastric, rectal, and duodenal epithelial cells [99]. Interplay of SARS-CoV-2 with ACE2 in the Gastrointestinal tract may causes damage to the barrier function by disrupting barrier proteins ZO-1, claudins, and occluding and enhance the inflammatory cytokine production, which as a result may cause dysbiosis and severity of intestinal inflammation $[111,112]$. In addition, intestinal inflammation may cause increase in dysbiosis and harm to the intestinal mucosal barrier function, dendritic cells, and the intestinal lymphocytes, and macrophages may conserve the cytokine storm [112]. Conditions such as diabetes, hypertension and obesity may have unfavorable effects on gut microbiome [113], and infection of SARS-CoV-2 and reduction in ACE2 function may intensify the gut microbial dysbiosis [92]. Proliferation of diabetes-induced dysbiosis by ACE2 shortage was noted [114]. 11.4-61.1\% of GI manifestation of individuals with COVID-19, with inconstant outbreak and graveness is observed. The majority GI symptoms that are associated with COVID-19 are lenient and self-limiting such as anorexia, diarrhea, vomiting (nausea) and abdominal pain $[88,99,115,116]$. Minimum number of patients are present with an acute abdomen with set of causes such as acute pancreatitis, acute appendicitis, bowel ischemia, intestinal obstruction, hemoperitoneum or abdominal compartment syndrome [116]. RNA of Severe acute respiratory syndrome coronavirus 2 has been existed in biopsies from all parts of the alimentary canal (esophagus, stomach, duodenal, rectum) [95]. Due to direct viral injury, there is involvement of GI tract and/or an inflammation in immune response and may causes malabsorption, disparity in intestinal secretions and gut mucosal integrity and activeness of the enteric nervous system [117].

\section{Conclusion}

SARS-CoV-2 virus is a new and unique virus, so studies are being done to study is its effects and pathogenesis. Vaccines have also been developed but no $100 \%$ vaccine or treatment is available due to the virus distinctive characteristics. More research is needed to find its exact impact on human organs and its treatment.

\section{References}

1. Li Q, Guan X, Wu P, Wang X, Zhou L, et al. Early Transmission Dynamics in Wuhan, China, of Novel Coronavirus-Infected Pneumonia. N Engl J Med. 2020; 382: 1199-1207.

PubMed: https://pubmed.ncbi.nlm.nih.gov/31995857/

2. Bogoch A, Watts A, Thomas-Bachli C, Huber MUG, Kraemer K. Pneumonia of unknown etiology in wuhan, China: potential for international spread via commercial air travel. J Trav Med. 2020; 27: taaa008.

PubMed: https://pubmed.ncbi.nlm.nih.gov/31943059/

3. Lu H, Stratton CW, Tang YW. Outbreak of pneumonia of unknown etiology in wuhan China: the mystery and the miracle. J Med Virol. 2020; 92: 401-402.

PubMed: https://pubmed.ncbi.nlm.nih.gov/31950516/

4. How does coronavirus kill? Clinicians trace a fero. 2020.

5. Jain U. Effect of COVID-19 on the Organs. Cureus. 2020; 12: e9540. PubMed: https://www.ncbi.nlm.nih.gov/pmc/articles/PMC7470660/

6. Mehta JL, Calcaterra G, Bassareo PP. COVID-19, thromboembolic risk, and Virchow's triad: Lesson from the past. Clin Cardiol. 2020; 43: 1362-1367.

PubMed: https://pubmed.ncbi.nlm.nih.gov/33176009/

7. Zheng YY, Ma YT, Zhang JY, Xie X. COVID-19 and the cardiovascular system. Nat Rev Cardiol. 2020; 17: 259-260.

PubMed: https://pubmed.ncbi.nlm.nih.gov/32139904/

8. Inciardi RM, Lupi L, Zaccone G, Italia L, Raffo M, et al. Cardiac involvement in a patient with coronavirus disease 2019 (COVID-19). JAMA Cardiol. 2020; 5: 819-824.

PubMed: https://pubmed.ncbi.nlm.nih.gov/32219357/

9. Ni W, Yang X, Yang D, Bao J, Li R, et al. Role of angiotensin-converting enzyme 2 (ACE2) in COVID-19. Crit Care. 2020; 24: 1-10. PubMed: https://pubmed.ncbi.nlm.nih.gov/32660650/

10. Wadman M, Couzin-Frankel J, Kaiser J, Matacic C. Rampage through the body, from brain to toes. 2020. https://www.sciencemag.org/ news/2020/04/how-does-coronavirus-kill-clinicians-trace-ferociousrampage-through-body-brain-toes

11. Guan WJ, Ni ZY, Hu YU, Liang WH, Ou CQ, et al. Clinical characteristics of coronavirus disease 2019 in China. New Eng J Med. 2020; 382 1708-1720.

12. Batiha O, Al-Deeb T, Al-zoubi EA, Alsharu E. Impact of COVID-19 and other viruses on reproductive health. Andrologia. 2020; 52: e13791. PubMed: https://pubmed.ncbi.nlm.nih.gov/32790205/

13. Fan C, Li K, Ding Y, Lu WL, Wang J. ACE2 expression in kidney and testis may cause kidney and testis damage after 2019-nCoV infection. MedRxiv. 2020.

14. Wang $Z, X u X$. scRNA-seq profiling of human testes reveals the presence of the ACE2 receptor, a target for SARS-CoV-2 infection in spermatogonia, leydig and sertoli Cells. Cells. 2020; 9: 920. PubMed: https://pubmed.ncbi.nlm.nih.gov/32283711/ 
15. Darlenski R, Tsankov N. COVID-19 pandemic and the skin: what should dermatologists know? Clin Dermatol. 2020; 38: 785-787. PubMed: https://pubmed.ncbi.nlm.nih.gov/33341217/

16. Foo CC, Goon ATJ, Leow YH, et al. Adverse skin reactions to personal protective equipment against severe acute respiratory syndrome--a descriptive study in Singapore. Contact Dermatitis. 2006; 55: 291-294. PubMed: https://pubmed.ncbi.nlm.nih.gov/17026695/

17. Xia J, Tong J, Liu M, Shen Y, Guo D, et al. Evaluation of coronavirus in tears and conjunctival secretions of patients with SARS-CoV-2 infection. J Med Virol. 2020; 92: 589-594.

PubMed: https://pubmed.ncbi.nlm.nih.gov/32100876/

18. Zhou L, Xu Z, Castiglione G, et al. ACE2 and TMPRSS2 are expressed on the human ocular surface, suggesting susceptibility to SARS-CoV-2 infection. BioRxiv. 2020; 92: 589-594.

PubMed: https://pubmed.ncbi.nlm.nih.gov/32100876/

19. Wu P, Duan F, Luo C, et al. Characteristics of ocular findings of patients with coronavirus disease 2019 (COVID-19) in Hubei province, China. JAMA Ophthalmol. 2020; 138: 575-578.

PubMed: https://pubmed.ncbi.nlm.nih.gov/32232433/

20. Seah I, Agrawal R. Can the coronavirus disease 2019 (COVID-19) affect the eyes? A review of coronaviruses and ocular implications in humans and animals. Ocul Immunol Inflamm. 2020; 28: 391-395. PubMed: https://pubmed.ncbi.nlm.nih.gov/32175797/

21. Hung ECW, Chim SSC, Chan PKS, et al. Detection of SARS coronavirus RNA in the cerebrospinal fluid of a patient with severe acute respiratory syndrome. Clin Chem. 2003; 49: 2107-2108. PubMed: https://pubmed.ncbi.nlm.nih.gov/14633896/

22. Lau K, Yu W, Chu C, Lau S, Sheng B. Possible central nervous system infection by SARS coronavirus. Emerg Infect Dis. 2004; 10: 342-344. PubMed: https://pubmed.ncbi.nlm.nih.gov/15030709/

23. Moriguchi T, Harii N, Goto J, Harada D, Sugawara H, et al. A first case of meningitis/encephalitis associated with SARS-Coronavirus-2. Int J Infect Dis. 2020; 94: 55-58.

PubMed: https://pubmed.ncbi.nlm.nih.gov/32251791/

24. Wang J, Jiang M, Chen X, Montaner LJ. Cytokine storm and leukocyte changes in mild versus severe SARS-CoV-2 infection: review of 3,939 COVID-19 patients in China and emerging pathogenesis and therapy concepts. J Leukoc Biol. 2020; 108: 17-41.

PubMed: https://pubmed.ncbi.nlm.nih.gov/32534467/

25. Bullen CK, Hogberg HT, Bahadirli-Talbott A, Bishai WR, Hartung T, et al. Infectability of human BrainSphere neurons suggests neurotropism of SARS-CoV-2. ALTEX 37. 2020; 665-671.

PubMed: https://pubmed.ncbi.nlm.nih.gov/32591839/

26. Erickson MA, Banks WA. Neuroimmune axes of the blood-brain barriers and blood-brain interfaces: bases for physiological regulation, disease states and pharmacological interventions. Pharmacol Rev. 2018; 70: 278-314.

PubMed: https://pubmed.ncbi.nlm.nih.gov/29496890/

27. Buzhdygan TP, DeOre BJ, Baldwin-Leclair A, Bullock TA, McGary HM, et al. The SARS-CoV-2 spike protein alters barrier function in 2D static and 3D microfluidic in-vitro models of the human blood-brain barrier. Neurobiol Dis. 2020; 146: 105131.

PubMed: https://pubmed.ncbi.nlm.nih.gov/33053430/

28. Li W, Moore MJ, Vasilieva N, Sui J, Wong SK, et al. Angiotensinconverting enzyme 2: a functional receptor for SARS coronavirus. Nature. 2003; 426: 450-454.

PubMed: https://pubmed.ncbi.nlm.nih.gov/14647384/

29. Hamming I, Timens W, Bulthuis MLC, Lely AT, Navis GJ, et al Tissue distribution of ACE2 protein, the functional receptor for SARS coronavirus. A first step in understanding SARS pathogenesis. J Pathol. 2004; 203: 631-637.

PubMed: https://pubmed.ncbi.nlm.nih.gov/15141377/

30. Netland J, Meyerholz DK, Moore S, Cassell M, Perlman S. Severe acute respiratory syndrome coronavirus infection causes neuronal death in the absence of encephalitis in mice transgenic for human ACE2. J Virol. 2008; 82: 7264-7275.

PubMed: https://pubmed.ncbi.nlm.nih.gov/18495771/

31. Ding $Y$, Wang $H$, Shen $H$, Li Z, Geng J, et al. The clinical pathology of severe acute respiratory syndrome (SARS): A report from China. $J$ Pathol. 2003; 200: 282-289.

PubMed: https://pubmed.ncbi.nlm.nih.gov/12845623/

32. Chen R, Wang K, Yu J, Howard D, French L, et al. The spatial and cell-type distribution of SARS-CoV-2 receptor ACE2 in the human and mouse brains. Front Neurol. 2021; 11: 573095.

PubMed: https://pubmed.ncbi.nlm.nih.gov/33551947/

33. Gu J, Gong E, Zhang B, Zheng J, Gao Z, et al. Multiple organ infection and the pathogenesis of SARS. J Exp Med. 2005; 202: 415-424. PubMed: https://pubmed.ncbi.nlm.nih.gov/16043521/

34. Helms J, Kremer S, Merdji H, Clere-JehI R, Schenck M, et al. Neurologic Features in Severe SARS-CoV-2 Infection. N Engl J Med. 2020; 382 2268-2270.

PubMed: https://pubmed.ncbi.nlm.nih.gov/32294339/

35. Pfefferbaum B, North CS. Mental health and the Covid-19 pandemic. $\mathrm{N}$ Engl J Med. 2020; 383: 510-512.

36. Feng Z, Diao B, Wang R, Wang G, Wang C, et al. The novel severe acute respiratory syndrome coronavirus 2 (SARS-CoV-2) directly decimates human spleens and lymph nodes. MedRxiv. 2020.

37. Peiris JS, Chu CM, Cheng VCC, Chan KS, Hung IFN, et al. Clinical progression and viral load in a community outbreak of coronavirusassociated SARS pneumonia: A prospective study. Lancet. 2003; 361 : 1767-1772.

PubMed: https://pubmed.ncbi.nlm.nih.gov/12781535/

38. Xu L, Liu J, Lu M, Yang D, Zheng X. Liver injury during highly pathogenic human coronavirus infections. Liver Int. 2020; 40: 998-1004. PubMed: https://pubmed.ncbi.nlm.nih.gov/32170806/

39. Zhang C, Shi L, Wang FS. Liver injury in COVID-19: management and challenges. Lancet Gastroenterol Hepatol. 2020; 5: 428-430. PubMed: https://pubmed.ncbi.nlm.nih.gov/32145190/

40. Yao XH, Li TY, He ZC, Ping YF, Liu HW, et al. A pathological report of three COVID-19 cases by minimal invasive autopsies. Chin J Pathol. 2020; 49: 411-417. PubMed: https://pubmed.ncbi.nlm.nih.gov/32172546/

41. Wang $F$, Wang $H$, Fan J, Zhang $Y$, Wang $H Q$. Zhao Pancreatic injury patterns in patients with COVID-19 pneumonia Gastroenterology. 2020; 5: 434-435

PubMed: https://pubmed.ncbi.nlm.nih.gov/32247022/

42. Inamdar S, Benias PC, Liu Y, Sejpal DV, Satapathy SK, et al. Prevalence, risk factors, and outcomes of hospitalized patients with COVID-19 presenting as acute pancreatitis. Gastroenterology. 2020; 159: 2226-2228.e2

PubMed: https://www.ncbi.nlm.nih.gov/pmc/articles/PMC7448741/

43. Al Mazrouei SS, Saeed GA, AI Helali AA. COVID-19-associated acute pancreatitis: a rare cause of acute abdomen. Radiol Case Rep. 2020 15: 1601-1603.

PubMed: https://pubmed.ncbi.nlm.nih.gov/32685078/

44. Hadi A, Werge M, Kristiansen KT, Pedersen UG, Karstensen JG, et al. Coronavirus disease-19 (COVID-19) associated with severe acute pancreatitis: case report on three family members. Pancreatology. 2020; 20: 665-667.

PubMed: https://pubmed.ncbi.nlm.nih.gov/32387082/

45. de-Madaria E, Capurso G. COVID-19 and acute pancreatitis: examining the causality. Nature Reviews Gastroenterol Hepatol. 2021; 18: 3-4. PubMed: https://pubmed.ncbi.nlm.nih.gov/33203968/

46. Liu F, Long X, Zou W, Fang M, Wu W, et al. Highly ACE2 expression in pancreas may cause pancreas damage after SARS-CoV-2 infection. 2020.

47. Deisl C, Simonin A, Anderegg M, Albano G, Kovacs G, et al. Sodium/ 
hydrogen exchanger NHA2 is critical for insulin secretion in $\beta$-cells. Proc Natl Acad Sci U S A. 2013; 110: 10004-10009.

PubMed: https://pubmed.ncbi.nIm.nih.gov/23720317/

48. Zhou L, Zhang M, Wang J, Gao J. Sars-Cov-2: underestimated damage to nervous system. Travel Med Infect Dis. 2020; 36: 101642.

PubMed: https://pubmed.ncbi.nlm.nih.gov/32220634/

49. Li T, Wang L, Wang H, Gao Y, Hu X, et al. Characteristics of laboratory indexes in COVID-19 patients with non-severe symptoms in Hefei City, China: diagnostic value in organ injuries. Eur J Clin Microbiol Infect Dis. 2020; 39: 2447-2455.

PubMed: https://pubmed.ncbi.nlm.nih.gov/32613308/

50. Christ Crain M, Hoorn EJ, Sherlock M, Thompson CJ, Wass JAH Endocrinology in the time of COVID-19: management of Hyponatraemia and diabetes Insipidus. Eur J Endocrinol. 2020; 183: G9-G15. PubMed: https://pubmed.ncbi.nlm.nih.gov/32380474/

51. Chen M, Zhou W, Xu W. Thyroid function analysis in 50 patients with COVID-19: a retrospective study. Thyroid. 2021; 31: 8-11.

PubMed: https://pubmed.ncbi.nlm.nih.gov/32600165/

52. Brancatella A, Ricci D, Viola N, Sgrò D, Santini F, et al. Subacute thyroiditis after sars-COV-2 infection. J Clin Endocrinol Metab. 2020; 105: dgaa276.

PubMed: https://pubmed.ncbi.nlm.nih.gov/32436948/

53. Gao W, Guo W, Guo Y, Shi M, Dong G, et al. Thyroid hormone concentrations in severely or critically ill patients with COVID-19. J Endocrinol Invest. 2021; 44: 1031-1040.

PubMed: https://pubmed.ncbi.nlm.nih.gov/33140379/

54. Lui DTW, Lee $\mathrm{CH}$, Chow WS, Lee ACH, Tam AR, et al. Thyroid dysfunction in relation to immune profile, disease status and outcome in 191 patients with COVID-19. J Clin Endocrinol Metab. 2020. PubMed: https://pubmed.ncbi.nlm.nih.gov/33141191/

55. Freire Santana M, Borba MGS, Baía-da-Silva DC, et al. Case report: adrenal pathology findings in severe COVID-19: an autopsy study. Am J Trop Med Hyg. 2020; 103: 1604-1607.

PubMed: https://pubmed.ncbi.nlm.nih.gov/32876012/

56. Liu J, Han P, Wu J, Gong J, Tian D. Prevalence and predictive value of hypocalcemia in severe COVID-19 patients. J Infect Public Health. 2020; 13: 1224-1228.

PubMed: https://pubmed.ncbi.nlm.nih.gov/32622796/

57. Elkattawy S, Alyacoub R, Ayad S, Pandya M, Eckman A. A novel case of hypoparathyroidism secondary to SARS-CoV-2 infection. Cureus. 2020; 12: e10097.

PubMed: https://pubmed.ncbi.nlm.nih.gov/33005518/

58. Bobaker A, Alzwi A. The effect of COVID-19 on parathyroid glands. J Infect Public Health. 2021; 14: 724-725.

PubMed: https://pubmed.ncbi.nlm.nih.gov/34020212/

59. Frankel M, Feldman I, Levine M, Frank Y, Bogot NR, et al. Bilatera adrenal hemorrhage in Coronavirus disease 2019 patient: a case report. J Clin Endocrinol Metab. 2020; 105: dgaa487.

PubMed: https://pubmed.ncbi.nlm.nih.gov/32738040/

60. Álvarez-Troncoso J, Zapatero Larrauri M, Montero Vega MD, et al Case report: COVID-19 with bilateral adrenal hemorrhage. Am J Trop Med Hyg. 2020; 103: 1156-1157.

PubMed: https://pubmed.ncbi.nlm.nih.gov/32682452/

61. Ma L, Xie W, Li D, Shi L, Mao Y, et al. Effect of SARS-CoV-2 infection upon male gonadal function: a single center-based study. 2020. PubMed: https://medrxiv.org/lookup

62. Muller I, Cannavaro D, Dazzi D, Covelli D, Mantovani G, et al. SARSCoV-2-related atypical thyroiditis. Lancet Diabetes Endocrinol. 2020 8: 739-741.

PubMed: https://pubmed.ncbi.nlm.nih.gov/32738929/

63. Channappanavar R, Fett C, Mack M, Ten Eyck PP, Meyerholz DK, et al. Sex-based differences in susceptibility to severe acute respiratory syndrome coronavirus infection. J Immunol. 2017; 198: 4046-4053.
PubMed: https://pubmed.ncbi.nlm.nih.gov/28373583/

64. Piticchio T, Le Moli R, Tumino D, Frasca F. Relationship between beta coronaviruses and the endocrine system: a new key to understand the COVID-19 pandemic-A comprehensive review. J Endocrinological Invest. 2021; 44: 1553-1570.

PubMed: https://pubmed.ncbi.nIm.nih.gov/33583003/

65. Zhou F, Yu T, Du R, Fan G, Liu Y, et al. Clinical course and risk factors for mortality of adult inpatients with COVID-19 in Wuhan, China: a retrospective cohort study. Lancet. 2020; 395: 1054-1062. PubMed: https://pubmed.ncbi.nlm.nih.gov/32171076/

66. Xu Z, Shi L, Wang Y, Zhang J, Huang L, et al. Pathological findings of COVID-19 associated with acute respiratory distress syndrome. Lancet Respirat Med. 2020; 8: 420-422.

PubMed: https://pubmed.ncbi.nlm.nih.gov/32085846/

67. Mo X, Jian W, Su Z, Chen M, Peng $H$, et al. Abnormal pulmonary function in COVID-19 patients at time of hospital discharge. Eur Respirat J. 2020; 55: 2001217.

PubMed: https://pubmed.ncbi.nlm.nih.gov/32381497/

68. https://www.lung.org/lung-health-diseases/lung-disease-lookup/ards

69. Wu C, Chen X, Cai Y, Zhou X, Xu S, et al. Risk factors associated with acute respiratory distress syndrome and death in patients with coronavirus disease 2019 pneumonia in Wuhan, China. JAMA Internal Med. 2020; 180: 934-943.

PubMed: https://pubmed.ncbi.nlm.nih.gov/32167524/

70. https://my.clevelandclinic.org/health/diseases/10959-pulmonaryfibrosis

71. Liu X, Zhou H, Zhou Y, Wu X, Zhao Y, et al. Risk factors associated with disease severity and length of hospital stay in COVID-19 patients. J Infect. 2020; 81: e95-e97.

PubMed: https://pubmed.ncbi.nlm.nih.gov/32305490/

72. Rai DK, Sharma $P$, Kumar R. Post covid 19 pulmonary fibrosis-Is it real threat? Indian J Tuberculo. 2021; 68: 330-333.

PubMed: https://pubmed.ncbi.nlm.nih.gov/34099197/

73. Guan WJ, Ni ZY, Hu Y, Liang WH, Ou CQ, et al. Clinical characteristics of coronavirus disease 2019 in China. New Eng J Med. 2020; 382: 1708-1720.

74. https://www.kidney.org/atoz/content/AcuteKidneylnjury

75. Xiao G, Hu H, Wu F, Sha T, Zeng Z, et al. Acute kidney injury in patients hospitalized with COVID-19 in Wuhan, China: a single-center retrospective observational study. J Southern Med Univers. 2021; 41: 157-163.

PubMed: https://pubmed.ncbi.nlm.nih.gov/33624587/

76. Benedetti C, Waldman M, Zaza G, Riella LV, Cravedi P. COVID-19 and the kidneys: an update. Front Med. 2020; 7: 423. PubMed: https://pubmed.ncbi.nlm.nih.gov/32793615/

77. Pei G, Zhang Z, Peng J, Liu L, Zhang C, et al. Renal involvement and early prognosis in patients with COVID-19 pneumonia. J Am Soci Nephrol. 2020; 31: 1157-1165.

PubMed: https://pubmed.ncbi.nIm.nih.gov/32345702/

78. Noble R, Tan MY, McCulloch T, Shantier M, Byrne C, et al. Collapsing glomerulopathy affecting native and transplant kidneys in individuals with COVID-19. Nephron. 2020; 144: 589-594.

PubMed: https://pubmed.ncbi.nlm.nih.gov/32894838/

79. Li Z, Wu M, Yao J, Guo J, Liao X, et al. Caution on kidney dysfunctions of COVID-19 patients. 2020.

80. Ostfeld E, Rubinstein E, Gazit E, Smetana Z. Effect of systemic antibiotics on the microbial flora of the external ear canal in hospitalized children. Pediatrics. 1977; 60: 364-366.

81. Nguyen DK, Jueng J, Maul TM, Wei JL. Middle ear effusion prevalence at time of tympanostomy before and during COVID-19 pandemic. Int $\mathrm{J}$ Pediat Otorhinolaryngol. 2021; 147: 110785.

PubMed: https://pubmed.ncbi.nlm.nih.gov/34116322/ 
82. Umashankar A, Prabhu P. Effect of Covid-19 on Individuals with Hearing Impairment in India. J Clin Diagnos Res. 2020; 14.

83. Ye G, Li Y, Lu M, Chen S, Luo Y, et al. Standardized Sampling by the Same Nurse Could Improve the Positive Rate and Consistency of the Throat Swabs to Detect COVID-19. 2020.

84. Lai T, Xiang F, Zeng J, Huang Y, Jia L, et al. Reliability of induced sputum test is greater than that of throat swab test for detecting SARSCoV-2 in patients with COVID-19: A multi-center cross-sectional study. Virulence. 2020; 11: 1394-1401.

PubMed: https://pubmed.ncbi.nlm.nih.gov/33073676/

85. Di Stadio A, Ralli M, Ricci G. Gender differences in COVID-19 infection. The estrogen effect on upper and lower airways. Can it help to figure out a treatment. Eur Rev Med Pharmacol Sci. 2020; 24: 5195-5196. PubMed: https://pubmed.ncbi.nIm.nih.gov/32495849/

86. Gallo O. Risk for COVID-19 infection in patients with tobacco smoke-associated cancers of the upper and lower airway. Eur Arch Otorhinolaryngol. 2021; 278: 2695-2702.

PubMed: https://pubmed.ncbi.nlm.nih.gov/33216184/

87. Travis CR. As plain as the nose on your face: the case for a nasal (mucosal) route of vaccine administration for Covid-19 disease prevention. Front Immunol. 2020; 11: 591897.

PubMed: https://www.ncbi.nlm.nih.gov/pmc/articles/PMC7561361/

88. Han C, Duan C, Zhang S, Spiegel B, Shi H, et al. Digestive symptoms in COVID-19 patients with mild disease severity: clinical presentation, stool viral RNA testing, and outcomes. Am J Gastroenterol. 2020; 115 916-923.

PubMed: https://pubmed.ncbi.nlm.nih.gov/32301761/

89. Parasa S, Desai M, Chandrasekar VT, Patel HK, Kennedy KF, et al Prevalence of gastrointestinal symptoms and fecal viral shedding in patients with coronavirus disease 2019: a systematic review and meta-analysis. JAMA Network Open. 2020; 3: e2011335-e2011335. PubMed: https://www.ncbi.nlm.nih.gov/pmc/articles/PMC7290409/

90. Almeida JFMD, Chehter EZ. COVID-19 and the gastrointestinal tract: what do we already know? Einstein (Sao Paulo). 2020; 18: eRW5909. PubMed: https://pubmed.ncbi.nlm.nih.gov/33206816/

91. Wu F, Zhao S, Yu B, Chen YM, Wang W, et al. A new coronavirus associated with human respiratory disease in China. Nature. 2020; 579: 265-269.

PubMed: https://pubmed.ncbi.nlm.nih.gov/32015508/

92. Hashimoto T, Perlot T, Rehman A, Trichereau J, Ishiguro H, et al. ACE2 links amino acid malnutrition to microbial ecology and intestinal inflammation. Nature. 2012; 487: 477-481.

93. Mao R, Qiu Y, He JS, Tan JY, Li XH, et al. Manifestations and prognosis of gastrointestinal and liver involvement in patients with COVID-19: a systematic review and meta-analysis. Lancet Gastroenterol Hepatol. 2020; 5: 667-678.

PubMed: https://pubmed.ncbi.nlm.nih.gov/32405603/

94. Zhang J, Garrett S, Sun J. Gastrointestinal symptoms, pathophysiology, and treatment in COVID-19. Genes Dis. 2021; 8: 385-400.

PubMed: https://pubmed.ncbi.nlm.nih.gov/33521210/

95. Lin L, Jiang X, Zhang Z, Huang S, Zhang Z, et al. Gastrointestinal symptoms of 95 cases with SARS-CoV-2 infection. Gut. 69: 997-1001. PubMed: https://pubmed.ncbi.nlm.nih.gov/32241899/

96. Effenberger M, Grabherr F, Mayr L, Schwaerzler J, Nairz M, et al. Faecal calprotectin indicates intestinal inflammation in COVID-19. Gut. 2020; 69: 1543-1544.

PubMed: https://pubmed.ncbi.nlm.nih.gov/32312790/

97. Burgueño JF, Reich A, Hazime H, Quintero MA, Fernandez I, et al. Expression of SARS-CoV-2 entry molecules ACE2 and TMPRSS2 in the gut of patients with IBD. Inflamm Bowel Dis. 2020; 26: 797-808. PubMed: https://pubmed.ncbi.nlm.nih.gov/32333601/

98. Harmer D, Gilbert M, Borman R, Clark KL. Quantitative mRNA expression profiling of ACE 2, a novel homologue of angiotensin converting enzyme. FEBS letters. 2002; 532: 107-110. PubMed: https://pubmed.ncbi.nlm.nih.gov/12459472/

99. Xiao F, Tang M, Zheng X, Liu Y, Li X, et al. Evidence for gastrointestinal infection of SARS-CoV-2. Gastroenterology. 2020; 158: 1831-1833. PubMed: https://pubmed.ncbi.nlm.nih.gov/32142773/

100. Du M, Cai G, Chen F, Christiani DC, Zhang Z, et al. Multiomics evaluation of gastrointestinal and other clinical characteristics of COVID-19. Gastroenterology. 2020; 158: 2298-2301. PubMed: https://pubmed.ncbi.nlm.nih.gov/32234303/

101. Luo S, Zhang X, Xu H. Don't overlook digestive symptoms in patients with 2019 novel coronavirus disease (COVID-19). Clin Gastroenterol Hepatol. 2020; 18: 1636-1637. PubMed: https://pubmed.ncbi.nlm.nih.gov/32205220/

102. Xu Y, Li X, Zhu B, Liang H, Fang C, et al. Characteristics of pediatric SARS-CoV-2 infection and potential evidence for persistent fecal viral shedding. Nat Medi. 2020; 26: 502-505. PubMed: https://pubmed.ncbi.nlm.nih.gov/32284613/

103. Xiong XL, Wong KKY, Chi SQ, Zhou AF, Tang JQ, et al. Comparative study of the clinical characteristics and epidemiological trend of 244 COVID-19 infected children with or without GI symptoms. Gut. 2021; 70: 436-438.

PubMed: https://pubmed.ncbi.nlm.nih.gov/32430348/

104. Cipriano M, Ruberti E, Giacalone A. Gastrointestinal infection could be new focus for coronavirus diagnosis. Cureus. 2020; 12: e7422. PubMed: https://pubmed.ncbi.nlm.nih.gov/32351807/

105. Hamming I, Timens W, Bulthuis MLC, Lely AT, Navis GV, et al Tissue distribution of ACE2 protein, the functional receptor for SARS coronavirus. A first step in understanding SARS pathogenesis. J Pathol. 2021; 203: 631-637.

PubMed: https://pubmed.ncbi.nlm.nih.gov/15141377/

106. Jiao L, Li H, Xu J, Yang M, Ma C, et al. The gastrointestinal tract is an alternative route for SARS-CoV-2 infection in a nonhuman primate model. Gastroenterology. 160: 1647-1661. PubMed: https://pubmed.ncbi.nlm.nih.gov/33307034/

107. Singer D, Camargo SM. Collectrin and ACE2 in renal and intestinal amino acid transport. Channels. 2011; 5: 410-423. PubMed: https://pubmed.ncbi.nlm.nih.gov/21814048/

108. Zhang H, Wada J, Hida K, Tsuchiyama Y, Hiragushi K, et al. Collectrin, a collecting duct-specific transmembrane glycoprotein, is a novel homolog of ACE2 and is developmentally regulated in embryonic kidneys. J Bio Chem. 276: 17132-17139.

PubMed: https://pubmed.ncbi.nlm.nih.gov/11278314/

109. Tian Y, Rong L, Nian W, He Y. Gastrointestinal features in COVID-19 and the possibility of faecal transmission. Aliment Pharmacol Therapeut. 2020; 51: 843-851.

PubMed: https://pubmed.ncbi.nlm.nih.gov/32222988/

110. Chen $Y$, Chen L, Deng Q, Zhang G, Wu K, et al. The presence of SARS-CoV-2 RNA in the feces of COVID-19 patients. J Med Virol. 2020; 92: 833-840.

PubMed: https://pubmed.ncbi.nlm.nih.gov/32243607/

111. Chen L, Li L, Han Y, Lv B, Zou S, et al. Tong-fu-li-fei decoction exerts a protective effect on intestinal barrier of sepsis in rats through upregulating ZO-1/occludin/claudin-1 expression. J Pharma Sci. 2020; 143: 89-96.

PubMed: https://pubmed.ncbi.nlm.nih.gov/32173265/

112. Fernández-Blanco JA, Estévez J, Shea-Donohue T, Martínez V, Vergara $P$. Changes in epithelial barrier function in response to parasitic infection: implications for IBD pathogenesis. J Crohn's Colitis. 2015; 9: 463-476.

PubMed: https://pubmed.ncbi.nlm.nih.gov/25820018/

113. Vandana UK, Barlaskar NH, Gulzar ABM, Laskar IH, Kumar D, et al. Linking gut microbiota with the human diseases. Bioinformation. 2020; 16: $196-208$

PubMed: https://pubmed.ncbi.nlm.nih.gov/32405173/ 
114. Duan Y, Prasad R, Feng D, Beli E, Calzi L, et al. Bone marrow-derived cells restore functional integrity of the gut epithelial and vascular barriers in a model of diabetes and ACE2 deficiency. Circulation Res. 2020; 125: 969-988.

PubMed: https://pubmed.ncbi.nlm.nih.gov/31610731/

115. Pan L, Mu M, Yang $P$, Sun $Y$, Wang $R$, et al. Clinical characteristics of COVID-19 patients with digestive symptoms in Hubei, China: a descriptive, cross-sectional, multicenter study. Am J Gastroenterol. 2020; 115: 766-773.

PubMed: https://pubmed.ncbi.nlm.nih.gov/32287140/
116. Seeliger B, Philouze G, Benotmane I, Mutter D, Pessaux P. Is the severe acute respiratory syndrome coronavirus 2 (SARS-CoV-2) present intraperitoneally in patients with coronavirus disease 2019 (COVID-19) infection undergoing emergency operations? Surgery. 2020; 168: 220-221.

PubMed: https://pubmed.ncbi.nlm.nih.gov/32591139/

117. Zhang $H$, Kang Z, Gong H, Xu D, Wang J, et al. Digestive system is a potential route of COVID-19: an analysis of single-cell coexpression pattern of key proteins in viral entry process. Gut. 2020; 69: 1010-1018. PubMed: https://www.ncbi.nlm.nih.gov/pmc/articles/PMC7211082/ 